\title{
FLEXIBLE WORKING ARRANGEMENT DAN PENGARUHNYA TERHADAP WORK-LIFE BALANCE PADA RESELLERS ONLINE SHOP
}

\author{
Reineldis Ina P. Hada ${ }^{1}$, Rolland Epafras Fanggidae ${ }^{2 *}$, Ni Putu Nursiani ${ }^{3}$ \\ 1,2,3Universitas Nusa Cendana, reineldispulohada23@gmail.com, \\ rolland_fanggidae@staf.undana.ac.id (Corresponding Author), \\ niputu.nursiani@staf.undana.ac.id
}

\begin{abstract}
ABSTRAK
Penelitian ini bertujuan untuk mengetahui bagaimana mendeskripsikan dan menganalisis pengaruh flexible working arrangement terhadap work-life balance pada Resellers Online shop di Kota Kupang. Metode yang digunakan dalam penelitian ini adalah metode survey. Instrumen yang digunakan dalam penelitian ini adalah kuisioner, wawancara, dan studi dokumentasi. Populasi penelitian ini yaitu, para resellers onine shop di kota Kupang yang menjual produk/barang melalui facebook. Teknik pengambilan sampel dalam penelitian ini menggunakan metode non probability sampling. Hasil penelitian menunjukkan bahwa, flexible working arrangement dapat membantu menyeimbangkan pekerjaan dan kehidupan pribadi terutama bagi mahasiswa, swasta, pegawai dan pekerjaan lainnya melalui analisis deskriptif. Sedangkan hasil penelitian menunjukkan flexible working arrangement berpengaruh positif dan signifikan terhadap work-life balance pada resellers online shop di kota Kupang.
\end{abstract}

Kata Kunci : flexible working arrangement, work-life balance, dan Resellers Online shop

\begin{abstract}
This study aims to find out how to describe and analyze the effect of flexible working arrangements on work-life balances on Resellers Online shop in Kupang City.The method used in research this is a survey method. The instrument used in This research is a questionnaire, interview, and documentation study. The population of this research is, online shop resellers in Kupang city who sell products / goods through Facebook. The sampling technique in this study uses amethod non probability sampling. The results showed that a flexible working arrangement can help balance work and personal life, especially for students, the private sector, employees and other work through descriptive analysis. While the results showed flexible working arrangements and a significant positive effect on the work-life balance on resellers online shop in the city of Kupang.
\end{abstract}

Keywords: flexible working arrangement, work-life balance, and resellers Online shop

Naskah diterima : 03-06-2020, Naskah dipublikasikan : 30-09-2020

\section{PENDAHULUAN}

Sumber daya manusia merupakan aset dan bagian terpenting bagi sebuah organisasi atau perusahaan karena perannya sebagai subjek kegiatan operasional perusahaan dan subjek pelaksana kebijakan atau sebagai penggerak bagi perusahaan (Poluan, 2018). Baiknya perkembangan dan pertumbuhan organisasi atau perusahaan akan ditunjang oleh sumber daya manusia yang berkompeten dan berkualitas karena semakin baik dan berkualitas sumber daya 
manusia maka semakin baik pula organisasi atau perusahaan tersebut. Sebagai kunci dari keberhasilan, perusahaan harus dapat menjamin sumber daya manusia dengan memberikan kenyamanan dan semangat dalam bekerja dalam hal ini tunjangan non fisik bukan hanya tunjangan fisik saja. Adapun faktor yang dapat mendukung kenyamanan dan semangat diantaranya keseimbangan pekerjaan dengan kehidupan pribadi, oleh karena itu dibutuhkan pengaturan kerja yang fleksibel (Poluan, 2018).

Pengaturan kerja yang fleksibel banyak diterapkan pada pekerjaan yang fleksibel seperti pekerjaan paruh waktu, pekerjaan yang memanfaatkan media online. Di antaranya online shop, atau organisasi atau perusahaan yang bekerja secara online. Semakin berkembangnya teknologi dan maraknya pembelian dan penjualan secara online maka pelaku usaha banyak yang mengembangkan usahanya dengan menarik pelaku usaha lainnya atau disebut resellers yang bertugas sebagai perantara pelaku usaha utama untuk menjual barang kembali kepada konsumen akhir atau tangan kedua pelaku usaha agar pelaku usaha utama tidak perlu menjual barang kepada konsumen akhir. Resellers merupakan seseorang yang menjual kembali produk dari pelaku usaha utama setelah penjual tersebut membelinya (Fitriani, Dimyati, \& Suroso, 2018). Resellers menjadi salah satu pekerjaan yang mulai diminati dan menjadikanya sebagai pekerjaan sampingan.

Selama ini banyak resellers yang mengandalkan penjualan secara konvensional dengan mengandalkan lokasi-lokasi strategis seperti perempatan jalan dan tempat-tempat umum lainnya. Namun sekarang dengan adanya online shop banyak resellers yang tidak megandalkan hal tersebut karena online shop tidak membutuhkan lokasi-lokasi strategi dan banyak keunggulan atau keuntungan yang diperoleh seperti tidak membutuhkan banyak biaya pemasaran hanya membutuhkan handphone, laptop dan sebagainya yang tersambung data atau jaringan wifi (Fitriani, Dimyati, \& Suroso, 2018). Keunggulan lainnya yang menjadi salah satu faktor penting adalah waktu yang fleksibel, dimana dapat digunakan dengan tidak ada batas waktu atau dapat digunakan kapan pun dan dimana pun atau adanya pengaturan kerja yang fleksibel sebagai keunggulannya.

Pengaturan kerja yang fleksibel atau flexible working arrangement merupakan sebuah alternatif pilihan yang diberikan untuk menentukan jadwal dan tempat bekerja (Rau \& Hyland, dalam Simanjuntak, dkk, 2019). Bentuk dari flexible working arrangement seperti flex-time, telecommuting, job-sharing, dan sebagainya. (Allen et al., dalam Fitriani, dkk, 2018) flex-time merupakan perubahan di lingkungan kerja seperti tidak perlu lama bekerja dalam jam yang sama atau dalam jam yang sudah ditetapkan dan tidak memerlukan penggurangan total jam kerja. Flextime dan telecommuting merupakan dua pilihan yang relatif banyak digunakan oleh pekerja. Telecommuting memungkinkan pekerja untuk melakukan pekerjaan dari tempat lain dengan bantuan teknologi (misalnya, komputer dan internet) dan flextime memungkinkan pekerja untuk memilih waktu memulai dan menyelesaikan pekerjaan berdasarkan persyaratan waktu yang telah dibuat (Allen, Golden, \& Shockley, 2015; Thompson, Payne, \& Taylor, 2015) dalam Fitriani, dkk, 2018). Pengaturan kerja yang fleksibel sudah banyak diterapkan diperusahaan-perusahaan dan banyak diterapkan pada masyarakat. Fleksibilitas pekerjaan memberikan perubahan dalam bekerja sehingga orang dapat bekerja tanpa memikirkan waktu dan tempat saat mereka melakukan pekerjaan tersebut.

Pekerjaan yang fleksibel atau bekerja tanpa memikirkan waktu dan tempat saat melakukan pekerjaan menjadi salah satu faktor pendorong orang menjadikan resellers online shop sebagai pekerjaan sampingan. Fleksibilitas jam kerja (flexible working arrangement) sendiri mulai populer pada awal tahun 1970-an (Sullivan dan Lussier, dalam Pandiangan, 2018). Dengan adanya jam kerja yang fleksibel lebih mudah membagi waktu antara keluarga dan 
karier, dan konsep dari jam kerja yang fleksibel ini dapat mengurangi konflik antara pekerjaan dan keluarga. Dalam hal ini flexible working arrangement berpengaruh pada keseimbangan antara pekerjaan dan kehidupan dengan hal lain akan membuat pekerja memberikan perfoma yang baik serta meningkatkan kepuasan dan produktivitas dari pekerja (Kelliher \& Anderson, 2010; Shagvaliyeva, S. \& Yazdanifard, R., 2013 dalam Fitriani, dkk, 2018). Dimana dengan waktu kerja yang fleksibel tidak akan menggangu antara pekerjaan dengan kehidupan terutama bagi resellers sendiri yang bekerja sesuai waktu yang ada ketika sedang diluar pekerjaan utamanya atau saat tidak sibuk dengan urusan keluarga.

Keseimbangan pekerjaan dan kehidupan atau yang biasa disebut sebagai work-life balance merupakan suatu keadaan seimbang pada dua tuntutan di mana pekerjaan dan kehidupan seorang individu adalah sama (Lockwood, 2003). Menurut Delecta (2011) work-life balance merupakan kemampuan seseorang atau individu untuk memenuhi tugas dalam pekerjaannya dan tetap berkomitmen pada keluarga mereka, serta tanggung jawab di luar pekerjaan lainnya. Oleh karena itu, diharapkan membuat atau membentuk work-life balance agar pekerja atau resellers dapat menyeimbangkan peran gandanya. Tidak hanya diharapkan untuk membuat kebijakan work-life balance, akan tetapi resellers seharusnya juga dapat menyeimbangkan perannya dan bekerja secara profesional agar keseimbangan kerja dapat terealisasi dengan baik antara pekerjaan utamanya dengan pekerjaan sampingannya sebagai resellers. Adannya flexible working arrangement akan mendukung work-life balance untuk memiliki kemudahan dalam mengatur keseimbangan antara pekerjaan dan kehidupan pribadi. Terhadap kedua hal tersebut dalam pekerjaan mereka ataupun kehidupan mereka dimana yang akan dilihat disini ialah bagaimana mereka mengatur kerja mereka yang fleksibel dalam bekerja sehingga mendapatkan keseimbangan antara pekerjaan dan kehidupan pribadi.

Banyaknya pengguna internet untuk online shop sendiri mulai mengalami peningkatan, survei yang dilakukan oleh Asosiasi Penyelenggara Jasa Internet Indonesia (APJII) di tahun 2017, jenis layanan yang diakses pengguna terbanyak adalah aplikasi chatting $(89,35 \%)$, media sosial $(87,13 \%)$, mesin pencari $(74,84 \%)$, lihat gambar/foto $(72,79 \%)$, lihat video $(69,64 \%)$, dan sisanya aktivitas berinternet lainnya. Sedangkan untuk penggunaan akses internet untuk online shop sendiri mulai mengalami peningkatan $23,4 \%$ ditandai dengan penggunaan sosial media untuk pejualan online shop $79,1 \%$ dan marketplace $25,4 \%$ dan penggunaan aplikasi online shop yang mengalami peningkatan baik dari jumlah pengguna untuk berbelanja maupun untuk berjualan.

Penggunaan facebook sebagai sosial media yang paling banyak digunakan dan dimanfaatkan sebagai alat untuk berbelanja maupun berjualan. Untuk kota kupang sendiri dapat dilihat dari banyaknya grup jual beli diantaranya BABE KUPANG dengan anggota 293.992, MARKETPLACE KUPANG dengan anggota 7016 dan lain sebagainya yang dapat dilihat langsung pada facebook dan marketplace pada fitur yang disiapkan oleh facebook (marketplace pada facebook bisa dilihat pada bagian atas disebelah fitur pesan atau messenger) dengan kebebasan jual beli tanpa diatur oleh facebook dalam artian facebook tidak berperan langsung.

\section{KAJIAN LITERATUR Work-life Balance}

Menurut Hill, 2001 Work-life balance (WLB) adalah dimana seseorang mampu menyeimbangkan tuntutan waktu, emosi, sikap, dan tanggung jawabnya pada pekerjaannya. Sedangkan menururt Lockwood (2003), work-life balance ialah suatu keadaan pada dua tuntutan dimana pekerjaan dan kehidupan seseorang yang seimbang. Hayman (2005) mengatakan adanya 3 dimensi pembentuk dari WLB, yaitu: 1) Work Interference With Personal 
Life (WIPL), sejauh mana pekerjaan dapat mengganggu kehidupan pribadi inidvidu. 2) Personal Life Interference With Work (PLIW), sejauh mana kehidupan pribadi menganggu pekerjaan individu. 3) Personal Life Enchancement Of Work (PLEW), sejauh mana kehidupan pribadi mampu meningkatkan kinerja individu pada pekerjaannya.Text artikel ditulis disini, text artikel ditulis disini, text artikel ditulis disini. Dari pengertian diatas dapat disimpulkan Work-life balance adalah bentuk dari kemampuan dan upaya seseorang dalam menyeimbangkan dua peran baik dalam pekerjaan maupun kehidupan.

Indikator-indikator untuk mengukur keseimbangan kehidupan-kerja menurut McDonald dan Bradley (2005) yaitu:

1. Keseimbangan waktu

2. Keseimbangan keterlibatan

3. Keseimbangan kepuasan

Menurut Schabracq, Winnubst dan Cooper (2003) dalam (Novi \& Jatmika, 2019), terdapat beberapa faktor yang memengaruhi work-life balance seseorang, yaitu: karakteristik kepribadian, karakteristik keluarga, karakteristik pekerjaan dan sikap.

\section{Flexible Working Arrangement}

Salah satu aspek penting untuk menarik atau mempertahankan pekerja adalah dengan memberikan fleksibilitas kerja atau yang lebih dikenal sebagai Flexible Work Arrangements (FWA). Fleksibilitas kerja diberikan sebagai bentuk variasi ketika bekerja, sehingga membuat para pekerja tidak merasa bosan (Wicaksono, 2019). Menurut Carlson dkk (2010) dalam (Wicaksono, 2019) fleksibilitas adalah kebijakan formal yang ditetapkan oleh manajemen sumber daya atau pengaturan informal terkait dengan fleksibilitas di tempat kerja. Sedangkan menurut Carlson dalam Wicaksono, (2019) mengartikan schedule flexibility sebagai pengaturan kerja secara fleksibel yang berarti pemilihan tempat dan waktu untuk bekerja, baik formal atau informal, yang memfasilitasi pekerja dalam kebijakan. Pemberian fleksibilitas kerja mempunyai keuntungan kepada pekerja terutama pekerja sampingan. Dari pengertian diatas dapat diartikan flexible work arrangement adalah salah satu upaya yang diberikan agar seseorang bertahan atau puas terhadap pekerjaannya karena kebebasan memilih dari waktu dan tempat untuk bekerja.

Indikator Fleksibilitas kerja Menurut Possenried dan Plantenga (2011) dalam (Wicaksono, 2019), flexible work arrangements (FWA) mempunyai tiga kategori secara umum, yaitu fleksibilitas dalam penjadwalan (scheduling), fleksibilitas dalam lokasi (telehomeworking), dan fleksibilitas dalam waktu (part-time). Menurut Carlson et al. (2010) schedule flexibility adalah pengaturan kerja secara fleksibel yang berarti pemilihan tempat dan waktu untuk bekerja, baik formal atau informal, yang memfasilitasi pekerja dalam kebijakan berapa lama (time flexibility), kapan (timing flexibility), dan di mana (place flexibility) bekerja.

1. Time flexibility : fleksibilitas dalam memodifikasi durasi kerja.

2. Timing flexibility : fleksibilitas dalam memilih jadwal kerjanya.

3. Place flexibility : fleksibilitas dalam memilih tempat kerjanya.

Flexible work arrangement memiliki tujuan pemberian jam kerja yang fleksibel dapat meningkatkan rasa tanggung jawab dan work life balance dari pekerja (Hofacker \& Konigm dalam Wicaksono, 2019). Kinicki dan Kreitner (2012) dalam (Wicaksono, 2019) berpendapat, bahwa kesehatan mental dari pekerja tersebut mempunyai pengaruh positif terhadap kepuasan kerja dari pekerja. Fleksibilitas kerja dapat menurunkan konflik pekerjaan-keluarga, menurunkan stres kerja yang dapat memengaruhi performa individu yang juga dapat mengakibatkan berkurangnya niat untuk hidup pekerja dan akhirnya menjadi keluar terutama pada pekerja wanita yang pada akhirnya akan memilih meneruskan tanggungjawab keluarga 
dibanding bertahan pada pekerjaan dan mengabaikan komitmen terhadap keluarga (Beham, dkk, 2012). Manfaat dari pengaturan jam kerja fleksibel antara lain (Selby dan Wilson, 2003) dalam (Pandiangan, 2018): Meningkatkan produktivitas, kepuasan kerja, semangat kerja, dan menggurangi ketidakhadiran dalam bekerja atau pengurangan kealpaan, dan pengurangan tingkat pengunduran diri, Menyeimbangkan antara pekerjaan dan kehidupan pribadi, misalnya memiliki waktu lebih banyak untuk keluarga. Dapat menghindari kerugian yang ditimbulkan dari jam sibuk, seperti stres yang ditimbulkan akibat kemacetan lalu lintas. Sehingga pekerja lebih produktif, bersemangat, dan termotivasi dalam bekerja dalam suasana nyaman dan berdampak pada kesehatan. Menimbulkan lingkungan kerja yang positif dalam arti dapat menggurangi persaingan untuk menghindari konflik dalam bekerja danjuga sebagai sarana untuk memunculkan bakat pekerja. Memiliki waktu yang lebih banyak dalam melakukan kegiatan yang disukai seperti hobi, pekerjaan sampingan, pendidikan dan lain-lain. Menghemat biaya atas pekerjaan dan penggunaan atas ruang atau gedung.

\section{Resellers Online shop}

Online shop adalah suatu proses jual-beli barang, jasa dan lain-lain yang dilakukan secara online tanpa bertemu secara langsung antara penjual dan pembeli. Atau online shop merupakan proses interaksi tanpa harus bertemu antara penjual dan pembeli yang dilakukan secara online.

Resellers adalah menjual kembali sebuah barang dari supplier tanpa adanya stok barang dengan komisi yang telah ditentukan sendiri atau dari supplier (Haryati, 2018). Sedangkan resellers online adalah kegiatan pembelian secara eceran yang dilakukan secara online melalui internet (Ekawati, 2012). Dalam pelaksanaan resellers online, konsumen melakukan pembelian eceran secara online melalui internet dengan fasilitas jejaring sosial yang ada melibatkan ritel yang melaksanakan perdagangan ritel secara online.

\section{Hubungan Antara Flexible Work Arrangements dan Work Life Balance}

Ketika seseorang memiliki pengaturan jam kerja yang fleksibel maka orang tersebut mampu mengatur jadwalnya sendiri. Dalam hal ini mampu menyeimbangkan pekerjaan dan kehidupan pribadinya secara lebih baik. Flexible work arrangement memiliki tujuan pemberian jam kerja yang fleksibel dapat meningkatkan rasa tanggung jawab dan work life balance dari pekerja (Hofacker dan Konigm 2013) dalam (Wicaksono, 2019). Pada penelitian sebelumnya yang dilakukan oleh Pandiangan (2018) didapatkan flexible work arrangement berpengaruh positif terhadap work life balance karena kepuasan dan kenyamanan yang dirasakan oleh pekerja. Faktor-faktor lain seperti peningkatan kinerja dan produktifitas karena adanya flexible work arrangement dalam memudahkan pekerja memiliki kebebasan dalam memilih dan mengatur sendiri jadwal kerja, tempat kerja maupun durasi atau lamanya bekerja. Ketika seseorang mendapatkan kebebasan seperti itu orang tersebut merasa lebih dihargai dan lebih memiliki waktu untuk keluarga sehingga pekerja tersebut terhindar dari stres kerja yang dapat menurunkan kinerja maupun produktifitasnya. Karena merasa nyaman dan puas sesorang akan lebih bertahan dan memilih untuk tetap pada pekerjaannya. Jadi dapat dikatakan ketika perusahaan atau organisasi menetapkan flexible work arrangement maka otomatis akan berpengaruh pada work life balance dari pekerja.

\section{METODE PENELITIAN}

Penelitian ini menggunakan metode survey. Dengan Teknik Pengumpulan Data berupa Kuesioner, Wawancara dan Studi Dokumentasi. Dalam penelitian ini, populasi yang digunakan adalah para resellers onine shop di kota Kupang yang menjual produk/barang melalui facebook, karena populasi yang digunakan adalah para konsumen yang bertindak sebagai resellers di kota 
Kupang yang melakukan pembelian baik online maupun tidak atau membeli langsung pada toko atau agen resellers di kota Kupang yang jumlahnya sangat banyak (tersebar dan sulit diketahui secara pasti), maka dilakukan pengambilan sampel untuk penelitian ini.

Teknik pengambilan sampling yang digunakan adalah dengan non probability sampling yaitu teknik sampling yang tidak memberikan kesempatan sama bagi setiap unsur atau anggota populasi untuk dijadikan sampel. Calon responden harus memiliki karakteristik tertentu, yaitu responden yang pernah melakukan pembelian di agen-agen atau toko fashion, kecantikan, digital, kuliner, dan produk lainnya secara online maupun bertemu langsung dengan agen-agen di kota Kupang dan bertindak sebagai resellers serta merupakan orang yang bekerja maupun yang belum bekerja yang menjadikan resellers hanya sebagai pekerjaan sampingan. Dan sampel untuk penelitian ini adalah 100 sampel atau 100 responden yang akan mengisi kuisioner.

\section{HASIL DAN PEMBAHASAN \\ Analisis Deskriptif}

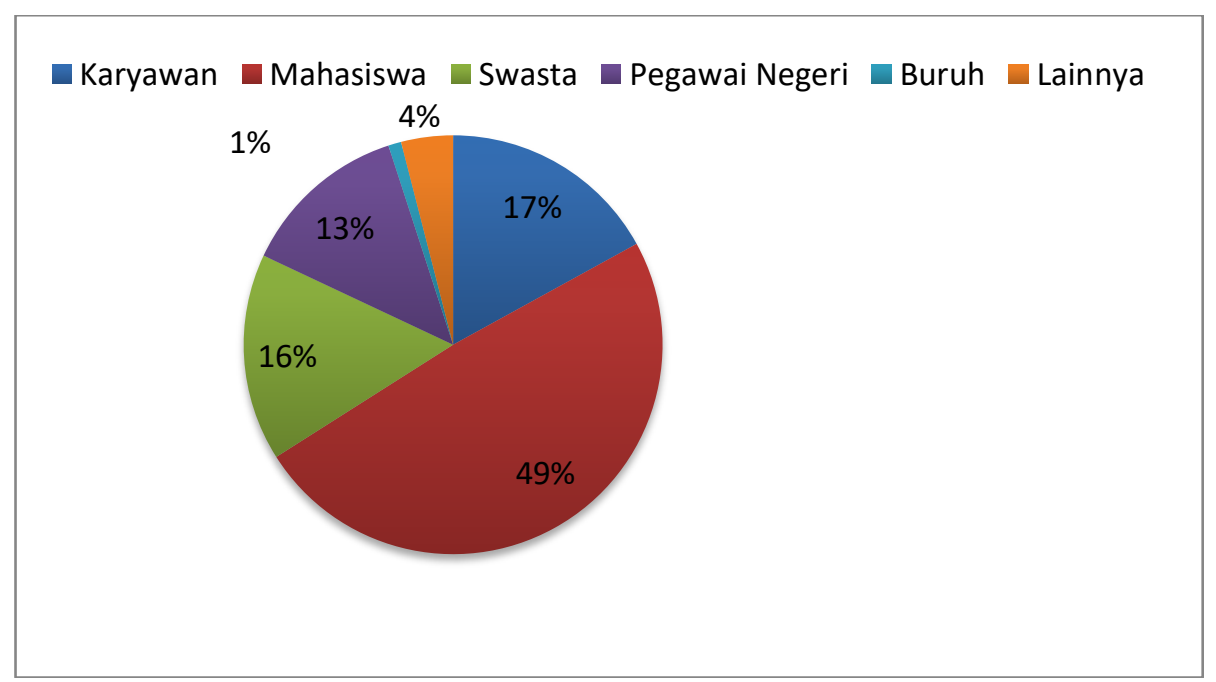

Gambar 1. Karakteristik Responden (Pekerjaan Utama)

Sumber : Data primer, 2020

Penelitian ini dilakukan dengan membagikan kuisioner kepada 100 responden. Pekerjaan utama responden paling banyak adalah mahasiswa dengan jumlah responden $49 \%$. Diantaranya 55\% berpendidikan SMA/SMK, menyusul responden yang berpendidikan S1 sebanyak 30 responden (30\%), sedangkan yang berpendidikan D3 yaitu sebanyk 12\% dan S2 sebanyak 1\%. Dan juga pada kategori umur 21-30 Tahun sebanyak 78\% yang berarti bahwa yang bekerja sebagai resellers kebanyakan berada pada rentang usia sangat produktif serta masa kerja 1-2 tahun dan lebih dari 2 tahun sebanyak 35\%. Dengan jenis produk yang paling banyak di jual adalah produk fashion $39 \%$ dan sebanyak $79 \%$ perempuan yang bekerja sebagai resellers dan yang berjenis kelamin laki-laki sebanyak $21 \%$. 


\section{Analisis Statistik (Regresi Sederhana)}

Tabel 1. Hasil Analisis Linear Regresi Sederhana

\begin{tabular}{|c|c|c|c|c|c|c|}
\hline \multicolumn{7}{|c|}{ Coefficients $^{\mathrm{a}}$} \\
\hline \multirow{2}{*}{\multicolumn{2}{|c|}{ Model }} & \multicolumn{2}{|c|}{ Unstandardized Coefficients } & \multirow{2}{*}{$\begin{array}{c}\text { Standardized } \\
\text { Coefficients } \\
\text { Beta }\end{array}$} & \multirow[t]{2}{*}{$t$} & \multirow[t]{2}{*}{ Sig. } \\
\hline & & $\mathrm{B}$ & Std. Error & & & \\
\hline & (Constant) & 3,025 & 3,114 & & ,971 & ,334 \\
\hline 1 & Flexible work arrangement & ,709 &, 068 &, 724 & 10,380 &, 000 \\
\hline
\end{tabular}

a. Dependent Variable: Work_life_balance

Sumber : Output SPSS data primer, 2020

$\mathrm{a}=$ angka konstan dari unstandardized coefficients. Dalam penelitian ini nilainya sebesar 3,025. Angka ini merupakan angka konstan yang mempunyai arti bahwa jika tidak ada flexible working arrangement (X) maka nilai konsisten work-life balance pada resellers (Y) adalah sebesar 3,025.

$\mathrm{b}=$ angka koefisien regresi. Nilainya sebesar 0,709. Angka ini menganung arti bahwa setiap penambahan $1 \%$ tingkat flexible working arrangement $(\mathrm{X})$, maka work-life balance $(\mathrm{Y})$ akan meningkat sebesar 0,709.

Karena nilai koefisien regresi bernilai (+), maka dengan demikian dapat dikatakan bahwa flexible working arrangement $(\mathrm{X})$ berpengaruh positif terhadap work-life balance $(\mathrm{Y})$. Sehingga persamaan regresi dapat dirumuskan sebagai berikut;

$$
\mathrm{Y}=3,025+0,709 \mathrm{X}
$$

Di mana: $\quad \mathrm{Y}=$ Work-life balance

$$
\mathrm{X}=\text { Flexible working arrangement }
$$

Tujuan penelitian ini adalah untuk mendeskripsikan flexible working arrangement dan work-life balance pada Resellers Online shop di Kota Kupang dan untuk menganalisis pengaruh flexible working arrangement terhadap work-life balance pada Resellers Online shop di Kota Kupang. Dari hasil penelitian pada uji deskriptif untuk variabel flexible working arrangement maupun variabel work-life balance berada pada kriteria sangat tinggi dengan persentase skor $91.18 \%$ dan $89.025 \%$. Hal ini berarti responden merasa sangat setuju dan setuju terhadap pengaturan kerja yang fleksibel yang membantu menyeimbangkan pekerjaan dan kehidupan pribadi.

Sedangkan pada uji t untuk menjawab tujuan dari rumusan masalah kedua tentang apakah flexible working arrangement berpengaruh terhadap work-life balance pada resellers resellers. Dari hasil penelitian ini diketahui bahwa flexible working arrangement berpengaruh positif terhadap work-life balance. Dan, dapat disimpulkan bahwa Ha diterima dan H0 ditolak yang artinya bahwa ada pengaruh signifikan antara flexible working arrangement dengan worklife balance. Hal ini juga dibuktikan dengan hasil kuesioner yang telah di isi oleh responden resellers Online shop terhadap sepuluh butir pertanyaan tentang flexible working arrangement dan sepuluh pertanyaan tentang work-life balance yang menghasilkan nilai R-square koefisien determinasi sebesar $52,4 \%$ dan $\mathrm{R}^{2}$ berada diantara 1 dan 0 atau berada ditengah berarti terdapat korelasi yang relatif kuat antara variabel bebas dengan variabel terikat. Hal ini berarti bahwa besarnya pengaruh flexible working arrangement terhadap work-life balance pada resellers 
Online shop sebesar 52,4\% dan sisanya di pengaruhi oleh faktor-faktor lain (Kepuasan kerja, motivasi kerja, karakteristik kepribadian, karakteristik keluarga, karakteristik pekerjaan dan sikap serta faktor lainnya).

Berdasarkan hasil di atas sesuai dengan penelitian yang dilakukan oleh Pandiangan (2008) mengatakan bahwa jam kerja fleksibel dapat meningkatkan kepuasan kerja dan meningkatkan driver untuk tetap tinggal di dalam suatu organisasi. Ketika keseimbangan dalam pekerjaan dan kehidupan pribadi berada pada tingkat kepuasaan yang tinggi, maka kemampuan kerja akan menjadi lebih baik dan berkualitas untuk memberikan konstribusi dan pelayan yang terbaik. Hal ini sejalan dengan penelitian sebelumnya tentang the impact of flexible working arrangement on work-life conflict and work pressure in ireland dimana hasil penelitian menunjukkan bahwa pekerjaan paruh waktu (flex-time) secara signifikan berpengaruh positif hal ini merupakan salah satu cara pioritas utama untuk mengatur keseimbangan antara pekerjaan dan kehidupan pribadi serta dapat mengurangi tekanan atau konflik antara pekerjaan dan keluarga. Kelebihan dari jam kerja fleksibel ini dapat menimbulkan dampak sisi positif terhadap lingkungan kerja, seperti dapat mengurangi rasa persaingan antara sesama dan selain itu juga dapat menghindari konflik dan stres kerja, sehingga pekerja lebih nyaman dan puas terhadap pekerjaannya yang fleksibel.

Berdasarkan pembahasan di atas hal ini sesuai dengan teori Hill, dkk (2008) mengatakan bahwa pengaturan jam kerja fleksibel mempunyai pengaruh positif dan signifikan bagi resellers. Fleksibilitas tempat kerja, lokasi kerja dapat didefinisikan sebagai kemampuan resellers untuk membuat perubahan, kapan dan berupa total waktu yang di habiskan dalam melakukan suatu pekerjaaan. Dapat dikatakan bahwa pengaturan jam kerja fleksibel memberikan lebih banyak kebebasan kepada resellers dalam mengatur jam kerja yang mereka inginkan terutama bagi mahasiswa. Bekerja dalam jam kerja fleksibel memungkinkan orang mengatur kehidupan sehari-hari mereka dengan lebih baik dan mengurangi konflik antara pekerjaan dan keluarga. Resellers yang diijinkan untuk memilih jam berapa mereka bisa memulai dan menyelesaikan pekerjaan cenderung lebih puas dengan pekerjaan mereka dan bagi mahasiswa yang memiliki banyak waktu luang diluar jam kuliah .

Berdasarkan hasil penelitian yang dilakukan pada resellers Online shop. Dapat disimpulkan secara keseluruhan bahwa penerapan flexible working arrangement berpengaruh positif dan dapat digunakan untuk menyeimbangkan antara pekerjaan dan kehidupan pribadi (work-life balance). Pengaturan jam kerja fleksibel mampu menurunkan tekanan maupun konflik antara pekerjaan dan keluarga dan terutama bagi mahasiswa dapat menurunkan tekanan akibat tugas dan kewajiban mereka seperti membeli buku dan modul dengan pendapatan yang mereka peroleh. Resellers yang memiliki kebebasan untuk memilih waktu dan tempat berapa diantara mereka bisa memulai dan menyelesaikan pekerjaan cenderung lebih puas dengan pekerjaan mereka sehingga berjalan secara harmoni.

\section{PENUTUP}

Simpulan

Flexible working arrangement dan work-life balance pada resellers online shop di kota Kupang, keduanya memiliki kriteria penilaian sangat tinggi pada hasil analisis deskriptif dimana, hal ini berarti adanya flexible working arrangement atau pengaturan kerja yang fleksibel dapat membantu menyeimbangkan pekerjaan dan kehidupan pribadi (work-life balance) terutama bagi mahasiswa, swasta, pegawai dan pekerjaan lainnya. 
Hasil uji hipotesis membuktikan bahwa variabel flexible working arrangement berpengaruh positif dan signifikan terhadap work-life balance pada resellers online shop di kota Kupang. Dengan nilai koefisien determinasi atau $\mathrm{R}^{2}$ berada pada korelasi yang kuat antara variabel bebas dengan variabel terikat.

\section{Saran}

Sebaiknya resellers online shop di kota Kupang perlu mempertahankan pengaturan jam kerja yang fleksibel dan pengaruh positif lainnya untuk pekerjaan utamanya. Dan lebih merasa puas dan nyaman dengan pekerjaan lainya meskipun waktu pekerjaannya kurang fleksibel. Dalam halnya mahasiswa sebagai dominan yang bekerja sampingan sebagai resellers dengan adanya pekerjaan yang fleksibel ini diharapkan bagi mahasiswa agar bekerja tanpa lupa melaksanakan kewajibannya sebagai mahasiswa.

Bagi peneliti selanjutnya diperlukan penelitian lebih lanjut dengan menambahkan faktofaktor di luar flexible working arrangement yang mana ikut mempengaruhi work-life balance pada resellers online shop di kota Kupang maupun di objek lainnya. Dan juga, peneliti dapat menambahkan variabel maupun teori tentang flexible working arrangement dan work-life balance dan melakukan penelitian-penelitian lainnya yang berkaitan dengan kedua teori tersebut.

\section{REFERENSI}

Bengngu, A., Amtiran, P. Y., \& Fanggidae, R. E. (2018). Impact of Part Time, Flextime and Reward on Productivity. Advances in Economics, Business and Management Research $3 r d$ International Conference on Tourism, Economics, Accounting, Management, and Social Science (TEAMS 2018), volume 69, 14.

Carlson, D. S., Grzywacz, J. G., Carolina, N., \& Kacmar, K. M. (2009). The relationship of schedule flexibility and outcomes via the work-family interface.

Cozby, P. C., \& Bates S. C. (2012). Methods in Behavioral Research-Eleventh Edition. New York: McGraw-Hill Companies

Delecta, P. 2011. Work Life Balance. International Journal of Current Research Vol. 33, Issue, 4, pp.186-189.

Ekawati, N. W. (2012). Jejaring Sosial/Facebook Sebagai Media E-Pengecer. Buletin Studi Ekonomi , 17 (2), 1-6.

Fitriani, L. R., Dimyati, M., \& Suroso, I. (2018, 02 07). Dinamika Reseller Pada Online Shop.

Haryati Rulita Penerapan Sistem Reseller Perspektif [Artikel] // Hukum Ekonomi Syariah (Hesy). - Lampung : Departemen Agama RI, AL-Qur'an Tajwid Terjemah, (Surabaya : CV Fajar Mulya), 23 Januari 2018. - Hal. 1-85.

Hill, E. J., Hawkins, A. J., Ferris, M., \& Weitzman, M. (2001). Finding An Extra Day A Week: The Positive Influence of Perceived Job Flexibility on Work and Family Life Balance. National Council on Family Relations, 50, 49-58.

Hill, J. E., Grzywacz, J. G., Allen, S., Blanchard, V. L., Matz-Costa, C., Shulkin, S., dan PittCatsouphes, M., (2008), Defining and conceptualizing workplace flexibility. Community, Work \& Family, 11 (2): 149-163.

Jatmika, D. dan Novi., (2019), Work-life Balance di Era Digital, Vol.5 No. 12 Juni 2019., ISSN 2477-1686.

Kelliher, C., \& Anderson, D. (2010). Doing more with less? Flexible working practices and the intensification of work. Human relations, 63, 83-106. doi:10.1177/0018726709349199

Kreitner, R., \& Kinicki, A. (2004). Organizational behavior. Fifth edition. New York: McGraw Hill. 
Lockwood, N. (2003). Work Life Balance: Challanges and Solutions, Society for Human Resource Management. Research Quarterly, 2, 1-12

McDonald, P., dan Bradley, L.M. 2005. The Case for Work/Life Balance: Closing the Gap Between Policy and Practice. 20:20 Series, 15 Nabila, M. (2018).

Novi, \& Jatmika, D. (2019). Work-life Balance di Era Digital. Work-life Balance di Era Digital $, 5,1-5$.

Pandiangan, H. (2018). Flexible Working Arrangement dan pengaruhnya terhadap Work-Life Balance pada Driver layanan transportasi online di kota Yogyakarta. Yogyakarta.

Poluan, A. R. (2018). Pengaruh Work-Life Balance, Beban Kerja Dan Gaya Kepemimpinan Terhadap Kinerja Pegawai PT. Bank Negara Indonesia (PERSERO) TBK, Kantor Cabang Manado. Jurnal Riset Bisnis dan Manajemen Vol 6 ,No.4, 2018: 347-356 , 6 (4), 347-356.

Rene, R., \& Wahyuni, S. (2018). Pengaruh Work-Life Balance Terhadap Komitmen Organisasi, Kepuasan Kerja, Dan Motivasi Kerja Terhadap Kinerja Individu Pada Karyawan Perusahaan Asuransi Di Jakarta. Jurnal Manajemen dan Bisnis Sriwijaya , 16 (1), 1-11.

Selby, C., dan Wilson, F., (2003) Flexible working handbook.

Simanjuntak, D. F., Mustika, M. D., \& Sjabadhyni, B. (2019, 6 1). Pengaruh Flexible Work Arrangement Terhadap Ethical Decision Making : Peran Employee Engagement Sebagai Mediator. Jurnal Diversita , 1-8.

Sullivan, S. dan Lussier, R., (1995), flexible working arrangement as Management tool: Part I 8 (8). hal. 4-17

Schabracq, M. J., Winnubst, J. A. M., \& Cooper, C. L. (2003). The handbook of work and health psychology. England: John Wiley \& Sons. Diunduh dari http://www.aledu.com/wp-content/uploads/2014/05/Handbook-of-Work-and-Health-Psychology-2Ed2003.pdf.

Shagvaliyeva, S. \& Yazdanifard, R. (2014). Impact of Flexible Working Hours on Work- Life Balance. American Journal of Industrial and Business Management, 4,20-23, DOI: http://dx.doi.org/10.4236/ajibm.2014.41004

Wicaksono, I. S. (2019). Pengaruh Kompensasi Dan Fleksibilitas Kerja Driver Gojek Terhadap Kinerja Dengan Kepuasan Kerja Sebagai Variabel Intervening. Yogyakarta: Imam Syaiful Wicaksono. 